\title{
PENGALAMAN KELUARGA MERAWAT KLIEN GANGGUAN JIWA PASCA PASUNG
}

\author{
(Family Experience In Taking Care Of Client Mental Disorders Post Restraint)
}

\author{
Hanik Endang Nihayati, Dwi Adinda Mukhalladah, Ilya Krisnana \\ Fakultas Keperawatan Universitas Airlangga Mulyorejo Kampus C Unair Surabaya \\ Email: azzam_psik@yahoo.com
}

\begin{abstract}
ABSTRAK
Pendahuluan: Pasca pasung sendiri adalah orang yang sudah terbebas dari pemasungan. Penelitian ini bertujuan untuk mendapatkan gambaran tentang pengalaman keluarga dalam merawat klien gangguan jiwa pasca pasung. Masalah terbesar yang timbul pada keluarga yang memiliki pengalaman merawat klien gangguan jiwa pasca pasung antara lain selalu mendampingi klien dalam kegiatan sehari-hari dan memastikan klien meminum obat. Metode: Penelitian ini menggunakan studi fenomenologi dengan 6 partisipan yang di wawancara mendalam. Partisipan adalah anggota keluarga yang merawat klien gangguan jiwa pasca pasung yang diperoleh melalui purposive sampling. Hasil: Setelah lepas pasung, klien gangguan jiwa juga mengalami kemajuan dibandingkan saat dipasung. Walaupun ada kemajuan, keluarga tetap mengamati perkembangan fisiknya, memberikan kegiatan kepada ODGJ, dan membawa ke pelayanan kesehatan. Selain itu, keluarga mengalami hambatan selama merawat klien gangguan jiwa pasca pasung dan ada juga yang tidak mengalami hambatan. Selama merawat klien, keluarga selalu berharap terjadi perubahan status kesehatan klien dan perubahan kesehatan. Keluarga juga mendukung supaya klien gangguan jiwa cepat sembuh. Diskusi: Pengalaman keluarga merawat klien gangguan jiwa pasca pasung yaitu merasa bersyukur karena setelah lepas pasung keadaan klien semakin membaik. Keluarga juga rutin memeriksakan klien ke petugas kesehatan. Selain itu, keluarga tidak akan memasung lagi klien gangguan jiwa tersebut. Keluarga membutuhkan intervensi untuk memperkuat mekanisme koping selama menghadapi berbagai masalah dalam merawat klien gangguan jiwa pasca pasung. Kegiatan tersebut dapat direalisasikan melalui penyediaan jasa konseling dan petugas kesehatan selalu mengkontrol keluarga serta klien tersebut.
\end{abstract}

Kata Kunci: Pengalaman Keluarga, Gangguan jiwa, Pasung

\begin{abstract}
Introduction: Post restraint is a person who is free from restraint. This study aims to describe about family experience in taking care of client mental disorders post restraint. The biggest problem in the family who has experience taking care of client mental disorders post restraint, among others, always assisting client in their daily activities and ensuring client are already taking the drugs. Method: This study used phenomenology design with six partisipan using indepth interview. The participant of this study was a member family caring for client mental disorders post restraint. This study employs the purposive sampling method. Result: After his release restraint, clients of mental disorders has also increased compared to when the restraint. Despite progress, the family still observe physical development, provide activities to ODGJ, and bring to healthcare. Families experiencing barriers for taking care of client mental disorders post restraint and some are not experiencing barriers. During the care of the clients, the family hopes a change in the client's health status and health change. The family also supports so that clients with mental disorders speedy recovery. Discussion: Family experience in taking care of client mental disorders post restraint are grateful that after restraint off the client state is getting better. The family also regularly check the client to the health worker. In addition, families will no longer restraint clients such mental disorders. Family need an intervention for strengthen coping mechanisms for dealing with various problems in caring for clients with mental disorders after restraint. These activities can be realized through the provision of counseling services and health workers always control the family as well as the client.
\end{abstract}

Key words: Family Experience, Mental Disorders, Restraint

\section{PENDAHULUAN}

Gangguan jiwa berat ini merupakan bentuk gangguan dalam fungsi alam pikiran berupa disorganisasi (kekacauan) dalam isi pikiran yang ditandai antara lain oleh gejala gangguan pemahaman (delusi, waham), gangguan persepsi, serta dijumpai daya realitas yang terganggu yang ditandai dengan perilaku aneh (Ferry \& Makhfudli, 2009). Pemasungan penderita gangguan jiwa adalah tindakan masyarakat terhadap penderita gangguan jiwa (biasanya yang berat) dengan cara dikurung, dirantai kakinya dimasukan kedalam balok kayu sehingga kebebasannya menjadi hilang. Pemasungan dilakukan oleh masyarakat disebabkan oleh beberapa alasan, yaitu masyarakat dan keluarga takut Orang Dengan Gangguan Jiwa (ODGJ) akan bunuh diri dan mencederai orang lain, ketidakmampuan keluarga merawat ODGJ, dan juga karena pemerintah tidak memberikan pelayanan kesehatan jiwa dasar pada ODGJ yang berada di komunitas (Minas $\&$ Diatri, 2008).

Pasca pasung sendiri adalah orang yang sudah terbebas dari pemasungan. Walaupun ODGJ sudah bebas dari pemasungan, beban pada keluarga klien ODGJ belum selesai. Hasil 
evaluasi dari 9 orang klien yang sudah lepas dari pemasungan, kemandirian mereka dalam perawatan diri sudah cukup optimal sehingga intervensi yang diberikan lebih berfokus kepada cara mempertahankan kepada status kemandirian tersebut (Sari, 2009).

Berdasarkan data dari World Health Organisasi (WHO) ada sekitar 450 juta orang di dunia yang mengalami gangguan jiwa. Hasil Riset Kesehatan Dasar (Riskesdas) tahun 2013, menunjukkan bahwa prevalensi gangguan mental emosional yang ditunjukkan dengan gejala-gejala depresi dan kecemasan adalah sebesar 6\% untuk usia 15 tahun ke atas atau sekitar 14 juta orang. Sedangkan, prevalensi gangguan jiwa berat, seperti schizophrenia adalah 1,7 per 1000 penduduk atau sekitar 400.000 orang. Prevalensi gangguan jiwa di Jawa Timur pada gangguan jiwa berat (psikosa/skizofrenia) sebanyak 0,22\% dan gangguan mental emosional sebesar 6,5\%. Data dari Dinas Kesehatan Kabupaten Jember tahun 2014 menyebutkan jumlah klien gangguan jiwa di Kabupaten Jember sebanyak 17.451 orang. Kementerian Kesehatan memperkirakan jumlah ODGJ yang mengalami pemasungan di seluruh Indonesia mencapai lebih 18 ribu jiwa. Proporsi keluarga yang memiliki ODGJ psikosis dan pernah melakukan pemasungan $14,3 \%$ atau sekitar 237 keluarga dari 1.655 keluarga yang memiliki ODGJ yang dipasung dan terbanyak pada keluarga di pedesaan $(18,2 \%)$ (Riskesdas, 2013). Prosentase keluarga yang memiliki ODGJ yang dipasung di Jawa Timur sebanyak 16,3\% (Riskesdas, 2013). Menurut data dari Dinas Kesehatan Kabupaten Jember, kasus pasung di Kabupaten Jember sampai pada tahun 2016 sebanyak 124 kasus dan pada wilayah kerja Puskesmas Rambipuji ada 10 kasus pasung yang 7 diantaranya ada di Desa Pecoro.

Beban yang ditanggung oleh keluarga yang hidup bersama penderita gangguan jiwa berat meliputi beberapa faktor, baik secara ekonomi maupun sosial. Selain itu, beban yang ditangguang keluarga berupa beban subjektif dan objektif, pengalaman stress seumur hidup, sehingga membuat koping tidak efektif (Yusuf, 2012). Kurangnya pengetahuan tentang gangguan jiwa serta motivasi keluarga untuk melakukan perawatan yang tepat pada klien gangguan jiwa menjadikan beban keluarga semakin kompleks.

Pada awalnya, ODGJ ini dipasung selama bertahun-tahun oleh keluarga. Akhirnya, oleh perangkat desa dan pemerintah Kabupaten Jember ODGJ di lepas pasungnya. Setelah terlepas dari pasung, Puskesmas Rambipuji memberikan pengobatan kepada klien tersebut. Upaya lain Puskesmas Rambipuji sendiri kepada klien pasca pasung adalah perawat selalu mengunjungi rumah klien tersebut untuk mengontrol obatnya masih tersedia atau tidak dan mengontrol klien tersebut apakah rutin meminum obat yang diberikan. Selain itu, klien pasca pasung sudah bisa diajak berkomunikasi, sudah mulai berani untuk keluar rumah, dan berkebun bersama keluarga.

Upaya pemerintah mengatasi masalah pemasungan dengan mencanangkan Indonesia Bebas Pasung 2014 sudah cukup baik. Hal ini dilakukan agar orang yang dipasung bisa bebas, karena kegiatan pasung adalah kegiatan yang melanggar Hak Asasi Manusia.

\section{METODE PENELITIAN}

Penelitian ini menggunakan desain riset kualitatif, yaitu suatu proses penelitian dan pemahaman yang berdasarkan pada metodologi yang menyelidiki suatu fenomena sosial dan masalah manusia. Pendekatan yang digunakan dalam penelitian ini adalah fenomenologi, yaitu cabang dari filosofi yang menekankan pengalaman manusia sebagai objek penelitian.

Dalam penelitian kualitatif tidak menggunakan istilah populasi, tetapi oleh Spradley dinamakan "social situtation" atau situasi sosial yang terdiri atas tiga elemen yaitu: tempat (place), pelaku (actors), dan aktivitas (activity) yang berinteraksi secara sinergis. Sampel dalam penelitian kualitatif bukan dinamakan responden, tetapi sebagai narasumber, atau partisipan, informan, teman dan guru dalam penelitian. Pengambilan sampling dalam penelitian ini menggunakan teknik sampling secara Purposive Sampling. Purposive Sampling adalah suatu teknik penetapan sampel dengan cara memilih sampel diantara populasi sesuai dengan yang dikehendaki peneliti (tujuan/masalah dalam penelitian), sehingga sampel tersebut dapat mewakili karakteristik populasi yang telah dikenal sebelumnya (Nursalam, 2008).

Peneliti menggunakan alat bantu pengumpul data berupa alat perekam berupa video kamera atau recorder dan catatan lapangan. Jika partisipan tidak bersedia menggunakan video kamera, peneliti merekam wawancara menggunakan recorder. Pada penelitian ini peneliti melakukan wawancara di Desa Pecoro Kecamatan Rambipuji Kabupaten Jember. Tahap penelitian berupa wawancara akan membutuhkan waktu satu 
minggu yang dimulai awal bulan Juni 2016 dan pengolahan data awal minggu ketiga bulan Juni 2016.

Peneliti melakukan analisis data dalam beberapa tahap (Hasbiansyah, 2008) yaitu: Tahap Awal, Tahap Horizonalization, dan Tahap Cluster of Meaning. Prinsip etik berdasarksn Pedoman Nasional Etik Penelitian Kesehatan (PNEPK) tahun 2004 terdiri atas tiga prinsip yaitu menghormati seseorang (Respect for persons), kemanfaatan (Beneficence), dan Keadilan (Justice). Ada empat kriteria untuk memperoleh keabsahan data yaitu derajat kepercayaan (credibility), keteralihan (transferability), kebergantungan (dependability), dan kepastian (cofirmability) (Guba dan Lincoln (1994) dalam Moleong, 2010).

\section{HASIL}

Hasil menelitian ini menunjukkan bahwa 6 partisipan dalam penelitian ini semua berjenis kelamin perempuan, beraga Islam, Suku Madura dengan usia 48-80 tahun.

Dalam fikiran beberapa keluarga, jika tidak dipasung dan klien ditinggal bekerja klien gangguan jiwa akan jalan-jalan, marahmarah, dan mencelakai orang lain sehingga keluarga tidak tenang. Selama merawat klien gangguan jiwa yang dipasung, anggota keluarga saling membantu dalam merawat klien tersebut. Jika keluarga ada yang bekerja, maka anggota keluarga yang lainnya yang membantu merawat memenuhi kebutuhan klien seperti makan dan minum. Selain itu, keluarga juga menceritakan sekalipun klien tersebut dipasung, klien juga bisa menciderai dirinya sendiri. Contohnya, klien akan memukulkan kepalanya ke tembok.

Pengalaman keluarga yang lainnya dalam merawat klien gangguan jiwa saat dipasung dirasakan sebagai beban psikologis. Beban psikologis dinyatakan oleh partisipan dalam bentuk takut, khawatir, berat/sulit. Perasaan takut disini disebabkan misalnya klien akan marah-marah dan menciderai orang lain yang ada disekitarnya. Perasaan khawatir juga dirasakan partisipan karena takut klien jika jalan-jalan dan partisipan takut jika dia mendapat masalah. Perasaan berat/sulit dirasakan partisipan karena tidak bisa bekerja. Partisipan tidak bisa bekerja karena selalu memikirkan klien jika ditinggal bekerj oleh partisipan. Penelitian ini menyebutkan keluarga merasakan beban psikologis yang dinyatakan dalam bentuk takut, khawatir, berat/sulit selama merawat klien gangguan jiwa saat dipasung. Beban psikologis ini merupakan akumulasi dari perasaan takut, khawatir, berat/sulit terhadap perilaku klien.

Partisipan mengungkapkan sekarang klien pasca pasung sudah bisa bekerja, membantu memenuhi kebutuhan anggota keluarga, dan membantu partisipan mengerjakan pekerjaan rumah. Bekerja yang dimaksud adalah klien sudah bisa mendapatkan penghasilan sehingga bisa membantu memenuhi keperluan keluarga. Klien juga bisa membantu mengerjakan pekerjaan rumah seperti menyapu, mengepel, menjaga warung, dan lain-lain. Keluarga juga tak lupa untuk memeriksakan klien ke pelayanan kesehatan dan mengambil obat untuk klien.

Pengalaman keluarga yang lain selama merawat klien gangguan jiwa pasca pasung adalah keluarga merasakan perasaan bersyukur. Perasaan ini muncul karena selama pasca pasung, klien mengalami perubahan kearah yang lebih baik. Partisipan juga mengungkapkan bahwa ini cobaan dari Allah dan partisipan harus melalui ujian ini dengan penuh kesabaran.

Hasil penelitian ini menyebutkan bahwa keluarga mampu mengidentifikasi adanya gangguan terhadap perkembangan fisiknya. Menurut peneliti, anggota keluarga seharusnya mengenali perubahan kesehatan anggota keluarga lainnya sekecil apapun perubahan itu.

\section{PEMBAHASAN}

Kondisi Orang Dengan Gangguan Jiwa (ODGJ) pasca pasung yang belum pulih total menjadi dasar pertimbangan keluarga untuk menyajikan variasi kegiatan dalam bentuk aktivitas apapun. Aktivitas ini dapat menurunkan kejenuhan dan mengisi waktu luang ODGJ. Penelitian ini juga menemukan beberapa upaya keluarga dalam memberikan perawatan bagi ODGJ pasca pasung dengan memenuhi aturan perawatan yang disarankan dokter atau petugas kesehatan lainnya.

Hambatan adalah hal yang ditemui dan menimbulkan kesulitan bagi keluarga selama merawat klien gangguan jiwa pasca pasung. Pada penelitian ini, peneliti menemukan ada partisipan yang mengalami hambatan dan ada juga yang tidak mengalami hambatan. Keluarga yang tidak mengalami hambatan mengungkapkan bahwa klien sekarang sudah bisa kerja, sudah bisa mandiri, dan sudah bisa ditinggal oleh orang tuanya. Peneliti mendapatkan keluarga yang mengalami hambatan dalam hal pekerjaan dan pengobatan. 
Hasil penelitian ini mengidentifikasi bahwa cara menghadapi hambatan adalah dengan cara membujuk klien dan modifikasi dalam meminum obat. Partisipan membujuk klien untuk bekerja agar bisa memenuhi kebutuhan klien. Partisipan lainnya adalah dengan cara pendampingan dalam pengobatan. Partisipan memastikan klien meminum obatnya dengan cara memodifikasi cara meminum obatnya.

Pemberdayaan keluarga merupakan salah satu cara juga yang digunakan untuk menghadapi permasalahan selama merawat klien gangguan jiwa pasca pasung. Salah satu pemberdayaan keluarga yang ditemukan dalam penelitian ini adalah pembagian peran.

Penelitian ini mengidentifikasi harapan keluarga selama merawat klien gangguan jiwa pasca pasung antara lain harapan akan status kesehatan klien dan perubahan kesehatan klien. Keluarga selalu menaruh harapan bahwa klien bisa sembuh total seperti dahulu lagi. Keluarga tidak menginginkan apa-apa selain klien tersebut sembuh seperti dahulu. Ketika klien sudah sembuh, partisipan juga menginginkan klien bekerja lebih baik lagi.

\section{SIMPULAN DAN SARAN}

\section{Simpulan}

Setelah lepas pasung, klien gangguan jiwa juga mengalami kemajuan dibandingkan saat dipasung. Keluarga merasa sangat besyukur sekali dengan keadaan yang sekarang. Keluarga dalam merawat klien gangguan jiwa pasca pasung sebaiknya menggunakan metode-metode untuk mencapai tujuan kesehatan keluarga. Metode merawatnya adalah dengan mengamati perkembangan fisiknya. Selain mengamati perkembangan fisiknya, keluarga juga memberikan kegiatan kepada klien gangguan jiwa pasca pasung.

Gangguan jiwa pasca pasung, ada keluarga yang tidak mengalami hambatan dan ada juga keluarga yang mengalami hambatan. Hambatan tersebut muncul pada saat tertentu saja. Tetapi hambatan tersebut bisa dilalui oleh keluarga. Ketika hambatan itu datang, keluarga memiliki cara tersendiri untuk melewatinya.

Selama merawat klien gangguan jiwa pasca pasung, keluarga menyampaikan harapan yang berhubungan dengan perkembangan klien. Perkembangan klien itu berupa perubahan status kesehatan klien dan perubahan kesehatan. Perkembangan klien ke arah yang lebih baik memang menjadi harapan utama keluarga yang merawat klien gangguan jiwa pasca pasung.

Selain itu, dari penelitian ini dapat disimpulkan juga bahwa keluarga tidak akan memasung lagi klien gangguan jiwa tersebut. Keluarga juga mendukung supaya klien gangguan jiwa cepat sembuh. Misalnya dengan cara tidak lupa untuk memberi obat kepada klien gangguan jiwa dari petugas kesehatan.

\section{Saran}

Pihak rumah sakit atau perawat jiwa, hendaknya melakukan intervensi untuk memperkuat mekanisme koping keluarga selama menghadapi berbagai masalah dalam merawat klien gangguan jiwa pasca pasung. Kegiatan tersebut dapat direalisasikan melalui penyediaan jasa konseling dan petugas kesehatan selalu mengkontrol keluarga serta klien tersebut.

Pihak pelayanan kesehatan sebaiknya menyusun program untuk menurunkan stigma di masyarakat guna memperkuat sistem dukungan sosial bagi keluarga yang merawat klien gangguan jiwa pasca pasung. Hal tersebut dapat diwujudkan melalui penyebaran leaflet dan penyuluhan.

Perawat seharusnya dapat memanfaatkan penelitian ini sebagai pedoman untuk mengembangkan pendekatan dalam hal mengajarkan keluarga untuk memilih strategi koping yang tepat serta memberdayakan kondisi psikologis keluarga selama merawat klien gangguan jiwa pasca pasung.

Peneliti disarankan untuk melanjutkan dan menggali lebih dalam tentang pemberdayaan keluarga dalam mengelola berbagai beban yang dihadapi sebagai dampak yang dirasakan dalam merawat klien gangguan jiwa pasca pasung melalui penelitian kualitatif. Selain itu, pola koping keluarga untuk menghadapi berbagai masalah dalam merawat klien gangguan jiwa pasca pasung dapat digali lebih jauh melalui penelitian kualitatif.

\section{KEPUSTAKAAN}

Efendi, F \& Makhfudli. 2009. Keperawatan Kesehatan Komunitas Teori dan Praktik dalam Keperawatan. Jakarta : Salemba Medika

Hasbiansyah, O. 2008. Pendekatan Fenomenologi : Pengantar PraktikPenelitian dalam Ilmu Sosial dan Komunikasi. Mediator. Vol 9 (1) Hal. 171-172

Minas, H., \& Diatri, H. 2008. Pasung: Physical restraint and confinement of the mentally ill in the 
community. International Journal of Mental Health Systems. Vol 2(1), 1-5. doi: 10.1186/17524458-2-8

Moleong, L J. 2010. Metodologi Penelitian Kualitatif. Bandung: PT Remaja Rosdakarya Offset

Nursalam. 2008. Konsep dan Penerapan Metodologi Penelitian Ilmu Keperawatan Pedoman Skripsi, Tesis, dan Instrumen Penelitian Keperawatan Edisi 2. Jakarta : Salemba Medika
Sari, H. 2009. Pengaruh Family Psychoeducation terhadap beban dan kemampuan keluarga dalam merawat klien pasung di Kabupaten Bireun. Thesis. Depok : Universitas Indonesia

Yusuf, A., Putra S.T., \& Probowati, Y. 2012. Peningkatan Coping Keluarga Dalam Merawat Pasien Gangguan Jiwa Melalui Terapi Spiritual Direction, Obedience, Dan Acceptance (Doa). Jurnal Ners. Vol 7 (2) 